\title{
Experimental evidence for a universal threshold characterizing wave-induced sea ice break-up
}

\author{
Joey J. Voermans ${ }^{1}$, Jean Rabault ${ }^{2,3}$, Kirill Filchuk ${ }^{4}$, Ivan Ryzhov ${ }^{4}$, Petra Heil ${ }^{5}$, Aleksey Marchenko ${ }^{6}$, Clarence \\ O. Collins III ${ }^{7}$, Mohammed Dabboor ${ }^{8}$, Graig Sutherland ${ }^{9}$, and Alexander V. Babanin ${ }^{1,10}$ \\ ${ }^{1}$ Department of Infrastructure Engineering, University of Melbourne, Parkville, Australia \\ ${ }^{2}$ Norwegian Meteorological Institute, Oslo, Norway \\ ${ }^{3}$ Department of Mathematics, University of Oslo, Oslo, Norway \\ ${ }^{4}$ Arctic and Antarctic Research Institute (AARI), St. Petersburg, Russian Federation \\ ${ }^{5}$ Australian Antarctic Division and Australian Antarctic Program Partnership, University of Tasmania, Hobart, Australia \\ ${ }^{6}$ The University Centre in Svalbard, Longyearbyen, Norway \\ ${ }^{7}$ Coastal and Hydraulics Laboratory, U.S. Army Engineering Research and Development Center, Duck, North Carolina, USA \\ ${ }^{8}$ Science and Technology Branch, Environment and Climate Change Canada, Dorval, Canada \\ ${ }^{9}$ Environmental Numerical Prediction Research, Environment and Climate Change Canada, Dorval, Canada \\ ${ }^{10}$ Laboratory for Regional Oceanography and Numerical Modeling, National Laboratory for Marine Science and Technology, \\ Qingdao, China
}

Correspondence: Joey J. Voermans (jvoermans@unimelb.edu.au)

Received: 16 July 2020 - Discussion started: 24 July 2020

Revised: 7 October 2020 - Accepted: 12 October 2020 - Published: 27 November 2020

\begin{abstract}
Waves can drastically transform a sea ice cover by inducing break-up over vast distances in the course of a few hours. However, relatively few detailed studies have described this phenomenon in a quantitative manner, and the process of sea ice break-up by waves needs to be further parameterized and verified before it can be reliably included in forecasting models. In the present work, we discuss sea ice break-up parameterization and demonstrate the existence of an observational threshold separating breaking and non-breaking cases. This threshold is based on information from two recent field campaigns, supplemented with existing observations of sea ice break-up. The data used cover a wide range of scales, from laboratory-grown sea ice to polar field observations. Remarkably, we show that both field and laboratory observations tend to converge to a single quantitative threshold at which the wave-induced sea ice breakup takes place, which opens a promising avenue for robust parametrization in operational forecasting models.
\end{abstract}

\section{Introduction}

Surface gravity waves can propagate tens to hundreds of kilometres into the ice pack before the ice fully dissipates their energy (e.g. Kohout et al., 2014; Stopa et al., 2018). In the process, waves flex the ice, imposing stress on the elastic and brittle ice sheet. When this stress exceeds a critical value, the sea ice will crack or break, creating large regions of broken ice floes with complex dynamics (Horvat et al., 2016; Hwang et al., 2017). Once broken, the ice is able to move more freely, reducing the attenuation of wave energy (e.g. Collins et al., 2015) and thereby allowing waves to penetrate even further into the ice pack. This drives a series of secondary processes in the coupled air-sea system that can further affect the properties of the ice, including enhanced upper-ocean mixing in sea-ice-covered waters (Thomas et al., 2019), sea ice drift (Boutin et al., 2020) and lateral melting of ice floes (Steele, 1992). Hence, the extent to which waves can impact the morphology of the sea ice cover is defined by the balance between wave energy dissipation as a function of sea ice properties on the one hand and the break-up of the sea ice by the stress imposed onto the ice by the waves on the other hand 
(e.g. Kohout and Meylan, 2008). Evidently, the complex and coupled processes of ice-induced wave attenuation and waveinduced sea ice break-up need to be understood, quantified and modeled before wave-ice interaction processes can be reasonably implemented in operational forecasting models.

Studies have, so far, mainly focused on the attenuation of wave energy in sea ice covers and identified a series of conservative and dissipative processes that damp wave energy in sea ice. These include wave scattering (e.g. Vaughan and Squire, 2007; Meylan and Bennetts, 2018), stress within the ice layer (e.g. Wang and Shen, 2010; Sutherland et al., 2019), turbulence (Liu and Mollo-Christensen, 1988; Voermans et al., 2019), brine migration (Marchenko and Cole, 2017) and interactions between ice floes (Rabault et al., 2019; Herman et al., 2019). Although there is still debate regarding when and where these processes are important (Thomson et al., 2018; Squire, 2020), they have been, to various degrees, parameterized, validated and/or implemented in numerical wave models (e.g. The WAVEWATCH III Development Group, 2019). Our understanding of wave-induced sea ice break-up is, however, significantly lacking, and few studies are available (with the notable exception of the studies by Crocker and Wadhams, 1989; Langhorne et al., 1998; Kohout and Meylan, 2008; Dumont et al., 2011; Williams et al., 2013a).

Fundamentally, wave-induced sea ice break-up is determined by a large set of highly environment-dependent wave and ice parameters. Those include the mechanical properties of sea ice (the flexural strength of the ice $\sigma$, elastic or Young's modulus $Y$ ); its material properties (ice salinity $S_{\text {ice }}$, ice temperature $T_{\mathrm{i}}$, water $\rho_{\mathrm{w}}$ and ice density $\rho_{\mathrm{ice}}$ ); the scale of the ice (ice thickness $h$ and horizontal length scale of the ice $L_{\text {ice }}$ ); and wave field characteristics (wave amplitude $a$ and wavelength $\lambda$ ), the gravitational acceleration $g$ and time $t$. We ignore surface tension and viscosity here due to the large length scales associated with the problem, though it is acknowledged that the ice viscosity could potentially play a role. We also ignore $L_{\text {ice }}$, the floe size, and focus on solid ice instead, that is, $L_{\text {ice }} \gg \lambda$. If we also consider the ice to be flexible enough to follow the wave surface reasonably well - that is, the ice is not thick enough to be rigid at the length scale of the wavelength - buoyancy effects might be ignored such that $\rho_{\mathrm{w}}, \rho_{\text {ice }}$ and $g$ are only of minor importance. The ice mechanical properties $\sigma$ and $Y$ are, perhaps, the most complex variables in this set as they are strongly related to the environmental conditions to which the ice was exposed at its formation and during the rest of its lifetime. In particular, exposure to the cyclic bending of the ice by waves not only can lower the flexural strength of the ice (e.g. Langhorne et al., 1998), commonly known as fatigue, but can also strengthen the ice when steady stress loads are applied to the ice (Murdza et al., 2020), such as by wind and currents, whereas local heterogeneities in sea ice can lead to localized concentration of stress. While these complexities are intrinsic to the physics of the wave-induced sea ice break-up problem, a full under- standing of these processes is outside the scope of this study. Here, we ignore the dependence of sea ice material properties on its history (or time $t$ ) and adopt the traditional dependence of $\sigma$ and $Y$ on the brine volume fraction of the ice $v_{\mathrm{b}}$ which has been related to the temperature and salinity of the ice, such that $\sigma=f\left(S_{\text {ice }}, T_{\text {ice }}\right)$ and $Y=f\left(S_{\text {ice }}, T_{\text {ice }}\right)$.

If we then define the wave-induced sea ice break-up similarity by a non-dimensional parameter $I_{\mathrm{br}}$ using the Pitheorem (Buckingham, 1914), the break-up problem can be formulated as

$I_{\mathrm{br}}=f\left(\frac{\sigma}{Y}, \frac{a}{\lambda}, \frac{h}{\lambda}\right)$.

where $\sigma / Y$ is the strain, $a / \lambda$ is the wave steepness and $h / \lambda$ is the relative ice thickness. The dependency of $I_{\mathrm{br}}$ on these parameters can be determined by considering the ice sheet as a thin elastic plate. This results in the flexural strain

$\varepsilon=\frac{h}{2} \frac{\partial^{2} \eta}{\partial x^{2}}$

where $\eta$ is the wave surface elevation in the horizontal direction $x$. Considering a periodic wave $\eta=a \sin (k x-\omega t)$, where $k=2 \pi / \lambda$ is the wave number and $\omega$ is the radian wave frequency, the maximum strain is defined as (e.g. Dumont et al., 2011)

$\varepsilon=\frac{2 \pi^{2} a h}{\lambda^{2}}$.

Assuming elastic behaviour of the ice layer, the strain can be considered proportional to the flexural strength $\sigma$ of the ice, i.e. $\varepsilon=\sigma / Y$. It then follows that a monochromatic wave will break the ice when $2 \pi^{2} a h Y / \sigma \lambda^{2}>1$. The waveinduced sea ice break-up parameter $I_{\mathrm{br}}$ is, therefore,

$I_{\mathrm{br}}=\frac{a h Y}{\sigma \lambda^{2}}$.

This break-up parameter is consistent with Eq. (1) and forms the basis of the recent wave-induced sea ice breakup scheme implemented in coupled wave-ice models (Kohout and Meylan, 2008; Dumont et al., 2011; Williams et al., 2013a, b; Ardhuin et al., 2018; Boutin et al., 2018; Boutin et al., 2020). It follows from Eqs. (3) and (4) that the break-up threshold for a monochromatic wave is approximately $I_{\mathrm{br}}=$ $1 / 2 \pi^{2} \approx 0.05$, or, strictly speaking, when fatigue and local sea ice heterogeneities are considered $I_{\mathrm{br}} \leq 0.05$. Boutin et al. (2018) proposed a threshold 3.6 times smaller, i.e. $I_{\mathrm{br}}=0.014$, based on statistical considerations that the relative maximum strain of a Gaussian random sea state is larger than that of a monochromatic wave. However, to the best of our knowledge, no study has extensively validated the value of the critical threshold $I_{\mathrm{br}}$, nor its universality across a wide range of wave and ice scales. Without convincing validation, the value of this threshold remains an ambiguous extra degree of freedom needed to configure the model and to fit 
to observations, making it difficult to confidently apply the model at a global scale.

Currently, the lack of a large number of wave-induced sea ice break-up observations and the uncertainties associated with these are arguably the foremost reasons for the uncertainty in parameterizing wave-induced sea ice break-up. Measuring wave and ice properties in the harsh polar environment is challenging, both logistically and technically, even in perfect weather conditions - itself a rare event, especially considering that sea ice break-up often happens during storms. Observing sea ice break-up requires either continuous visual observations or refined experimental techniques. Even in the event that sea ice break-up is observed, identification of the exact instant at which the ice breaks (that is, the individual wave responsible for the break-up event) is problematic, as it does not necessarily identify the critical threshold of $I_{\mathrm{br}}$, but rather presents a sufficient condition for break-up. That means that, if a wave with known amplitude is observed in the sea ice cover and triggers ice breakup, all that is known is that any wave with the same wavelength and an amplitude equal to or larger than the amplitude recorded will break the ice. The contrapositive is true for any wave-induced ice motion taking place without breaking the ice cover. This is further complicated by the deterministic nature of the break-up event itself; that is, in theory we could measure the exact wave event responsible for the break-up, while, in contrast, the identified wave event is a result of the incoherent nature of the wave field and is, therefore, related to the statistical properties of the wave field instead. To shed light on this question, we suggest that many observations of wave-induced sea ice break-up and wave-induced sea ice motion without break-up should be collected. Then, if there should exist a critical universal threshold for $I_{\mathrm{br}}$ as defined in Eq. (4), a clear separation between unbroken and broken ice conditions should be observed, independently of the details of the ice conditions.

In this study, we attempt to perform such an analysis. For this, we use the results of wave-induced ice motion measurements from two recent field campaigns, one in the Antarctic and the other in the Arctic. In addition, the data obtained are also complemented with an extensive set of observations from both laboratory and field experiments, collected throughout the literature. Thereafter, we approximate the critical wave-induced sea ice break-up criterion based on all data combined and identify a universal threshold for $I_{\mathrm{br}}$.

\section{Methods}

\subsection{Field experiments}

In the present study, the focus is on data from two recent field experiments, aiming to measure the wave-induced ice motion leading to sea ice break-up. The first experiment took place in the Antarctic ice pack, and the second in the Arctic ice pack.

\subsubsection{Deployment in the Antarctic}

The Antarctic deployments occurred on (land)fast ice on the eastern rim of the Amery Ice Shelf $\left(69.2^{\circ} \mathrm{S}, 76.3^{\circ} \mathrm{E}\right.$; see Fig. 1a) on 7 December 2019. The instruments deployed consisted of two wave buoys, denoted as WB in the following (Spotter buoys, from Sofar Ocean Technologies), and two low-cost open-source ice motion loggers (Rabault et al., 2020; hereafter referred to as ice buoys and denoted IB). Both the wave and ice buoys are compact solar-charged position- and motion-recording instruments with real-time iridium transmission capability. The wave buoys measure displacement at $2.5 \mathrm{~Hz}$ using GPS and transmit wave and position data at a user-defined interval. For the deployment period considered here, only integral wave parameters and battery power status were transmitted every half an hour. The ice buoys measure the ice motion using an inertial motion unit (IMU) performing measurements at $10 \mathrm{~Hz}$ and transmit the full wave spectrum, geographical location and battery power status at a predefined interval, here, every $3 \mathrm{~h}$. The accuracy of the vertical displacement is approximately $0.02 \mathrm{~m}$ for the wave buoy. For high-frequency waves, the accuracy of the ice buoy is $O(\mathrm{~mm})$ (Rabault et al., 2016), but the noise level increases with decreasing wave frequencies (Rabault et al., 2020). For more technical details on the wave and ice buoys the reader is referred to Raghukumar et al. (2019) and Rabault et al. (2020), respectively.

The instruments were deployed along a line perpendicular to the unbroken ice edge. The first wave buoy (WB1) is about 100-200 $\mathrm{m}$ from the edge (see inset Fig. 1a). The second wave buoy (WB2) and first ice buoy (IB1) are deployed $3.7 \mathrm{~km}$ from the solid ice edge, close to each other (the initial distance between WB2 and IB1 is around $40 \mathrm{~m}$ ), whereas the last ice buoy (IB2) was deployed about $9.3 \mathrm{~km}$ from the edge. Wave buoys were deployed closest to the solid ice edge as these buoys are capable of surviving in the open water. While the ice buoys have sufficient buoyancy to float, they are expected to malfunction quickly after entering the water. At the time of deployment, the ice was estimated to be between 1 and $1.2 \mathrm{~m}$ thick.

No drift or significant wave events were recorded for the first 3 weeks after deployment. On 2 January 2020 the uniform fast ice, on which all instruments rested, broke, and all instruments drifted with the sea ice. In the weeks that followed, geographical location and vertical ice motion under the influence of waves were obtained until instruments stopped transmitting. End of transmission happened for IB2 on 22 January, for WB1 and WB2 on 1 February, and for IB1 on 10 March. It is noteworthy that WB2 reconnected on 3 March for half a day. The wave buoys failed due to depleted batteries, most likely caused by snow or ice coverage of the solar panels. Considering that batteries of the ice buoys were 

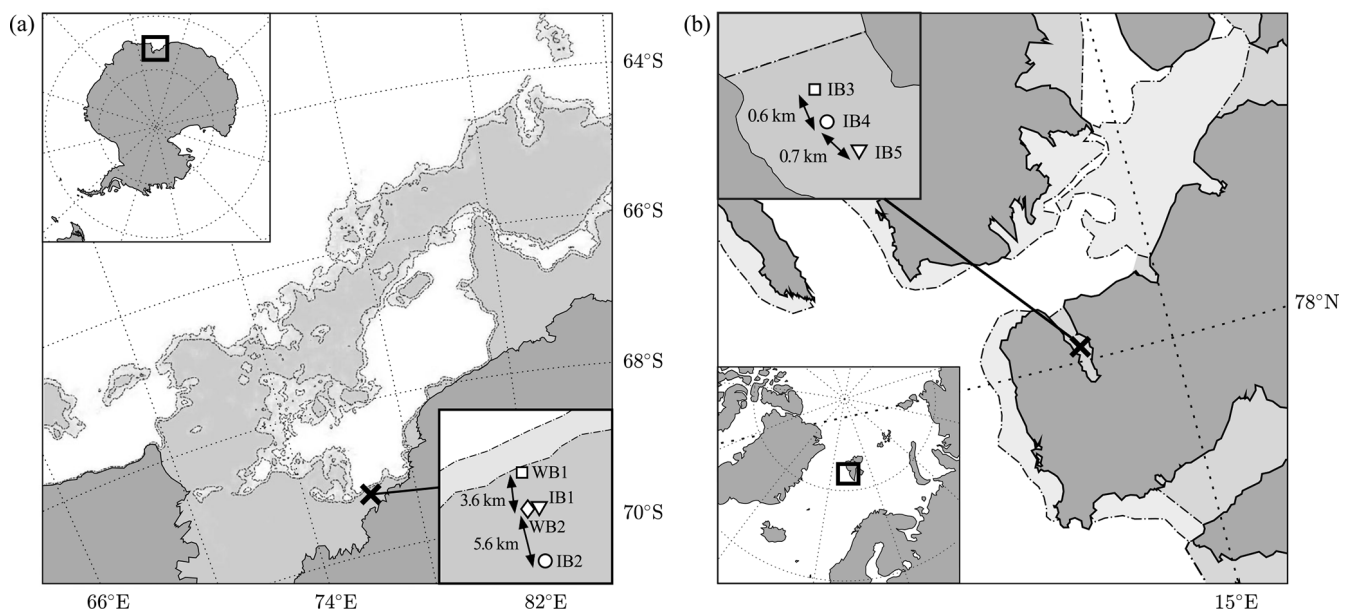

Figure 1. Map of the field experiment sites on (a) Antarctic fast sea ice and (b) fast ice in Svalbard. Deployment sites are indicated by a cross. Continents are shaded dark grey, whereas sea ice concentration is represented by the light grey shades using two contour levels, indicative of (a) sea ice concentration of 25 and $75 \%$ derived from AMSR2 for 2 January 2020 (Spreen et al., 2008) for light and dark grey, respectively, and (b) open drift ice and very close drift ice obtained from the Norwegian Meteorological Institute Ice Service for 23 March 2020 for light and dark grey, respectively. Instruments were deployed along a line perpendicular to the unbroken ice edge (see insets) and consisted of wave buoys (WB: Spotter buoys, Sofar Ocean Technologies) and open-source ice motion loggers (referred to as ice buoys, IB; Rabault et al., 2020). Note that in (a) IB1 is shifted laterally for visualization purposes, but in reality it is only $40 \mathrm{~m}$ apart from WB2.

still close to fully charged during the last transmissions received from both instruments, we suspect the ice buoys were damaged by the ice or ended up in the water between floes. As our interest is in wave-induced sea ice break-up, this study focuses on observations obtained from 2 to 8 January, which is the period over which initial sea ice break-up was observed for an extensive stretch of fast ice.

During the first week of January, sea ice concentration is well represented by the ice concentration map shown in Fig. 1a. A polynya of approximately $100 \mathrm{~km} \times 300 \mathrm{~km}$ separated the fast ice from a $100 \mathrm{~km}$ wide band of pack ice. Based on ERA5 re-analysis, three significant low-pressure systems passed along the Antarctic continent over the time interval considered. The first merely skimmed the deployment site on 2 January (Fig. 2a), while the second moved north-east just before reaching the longitude of the instruments around 5 January. The third low-pressure system is expected to have the largest impact on the conditions near the deployment site, with an estimated wind speed of about $10-15 \mathrm{~m} \mathrm{~s}^{-1}$ on 7 January (Fig. 2b).

\subsubsection{Deployment in the Arctic}

The second field experiment was performed in Grønfjorden, Svalbard (Fig. 1b). Three ice buoys were deployed on landfast sea ice between 10 and 13 March 2020, and recovered on 28 March. The unbroken ice edge was reasonably stable during the deployment, located roughly halfway through the fjord. The first ice buoy (IB3) was deployed approximately $500 \mathrm{~m}$ from the unbroken ice edge. The second (IB4) and third ice buoy (IB5) were deployed 600 and $700 \mathrm{~m}$ apart. Ice thicknesses of $0.3-0.4 \mathrm{~m}$ were measured along the main axis of the fjord at the start of the experiment. Based on the water temperature measured just under the ice and on the air temperature, the ice temperature is estimated to be about $-8^{\circ} \mathrm{C}$. The salinity of the ice was determined by measuring the conductivity of melted sections of a $0.4 \mathrm{~m}$ long ice core, with bulk salinity of $0.68 \%$. Based on visual observations, the ice did not break during this field experiment.

\subsection{Observations of sea ice break-up in previous literature}

In addition to the ice motion and break-up observations collected during our field campaigns, a set of wave-induced break-up data was collected from the literature. Published data were used only when sufficient details about the wave and ice conditions were presented to determine $I_{\mathrm{br}}$. Due to the near absence of concurrent measurements of all wave and ice properties, we consider it to be sufficient when ice thickness, wave height and wavelength (or wave period) are provided. The most critical requirement was that the published sea ice break-up event was, with sufficient confidence, attributed to the observed wave event. We exclude freshwater ice experiments and numerical studies.

The full data set consists of 31 observations, including 14 wave events that did not result in ice break-up (9 of them from the laboratory) and 17 events where waves were responsible for the break-up of the ice ( 7 of which are laboratory observations). Besides the laboratory study of Herman et al. (2018), field observations were taken from Liu and MolloChristensen (1988), Cathles et al. (2009), Marchenko et al. 


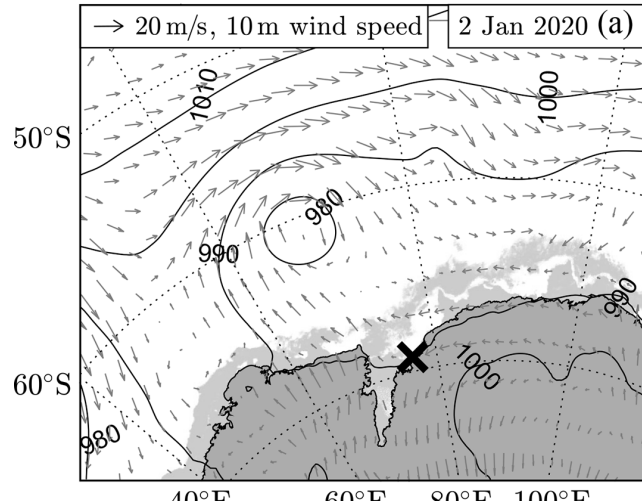

$40^{\circ} \mathrm{E}$

$60^{\circ} \mathrm{E} \quad 80^{\circ} \mathrm{E} \quad 100^{\circ} \mathrm{E}$

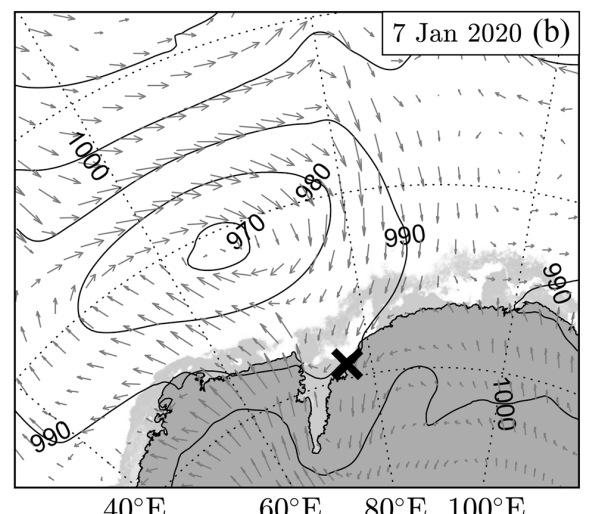

$60^{\circ} \mathrm{E} \quad 80^{\circ} \mathrm{E} \quad 100^{\circ} \mathrm{E}$

Figure 2. Passage of two storms offshore of the Antarctic instrument site on (a) 2 January 2020 and (b) 7 January 2020. Contours show mean sea level pressure, and wind speed at $10 \mathrm{~m}$ is displayed through the vector field (both from ERA5). Light grey shading represents sea ice, derived from AMSR2 data (Spreen et al., 2008). The black cross identifies the deployment site. The presence of relatively high wind speeds over the polynya region on 7 January 2020 is expected to have generated wind waves at the deployment site.

(2011), Marchenko et al. (2012), Asplin et al. (2012), Collins et al. (2015), Sutherland and Rabault (2016), Kohout et al. (2016), Marchenko et al. (2019) and Kovalev et al. (2020). We note that the break-up observations made by Liu and Mollo-Christensen (1988) and Kohout et al. (2016) are visual shipborne observations and not in situ measurements (see the complete set in Table 1).

In the case of the field experiment of Kovalev et al. (2020), wave conditions resulting in the largest $I_{\mathrm{br}}$ were used here as these are the waves most likely responsible for the break-up event observed. For the field observations of Sutherland and Rabault (2016), cracks in the ice were argued to be responsible for the sudden change in the dispersion relation from flexural-gravity waves to gravity waves, and this transition is used here to determine the instant at which the ice was broken by waves. Additionally, the study of Cathles et al. (2009) is included and describes the impact of swell on the flexure of the Ross Ice Shelf. Cathles et al. (2009) argue about the potential of most energetic swell events to promote crack propagation of the Nascent Iceberg. In a later study, Massom et al. (2018) showed that there exists a strong correlation between the arrival of swell and the disintegration of the ice shelves. The ice motion amplitudes observed in Cathles et al. (2009) are similar to those measured by Bromirski et al. (2010). While the ice shelf cannot be regarded as a thin ice sheet (and hence the validity of Eq. 2 for this event can be questioned), this observation is, nevertheless, included for comparison reasons.

As not all parameters were consistently and/or accurately measured across these studies, the uncertainty of the individual variables was estimated to approximate the uncertainty in $I_{\mathrm{br}}$. Each variable was described by a triangular probability distribution, the most likely value of which is typically the value given in the respective study or, alternatively, the mean of the provided range. To obtain an uncertainty for the wave-induced sea ice break-up parameter, a large number of random values for each variable were generated and the 5th and 95th percentiles of $I_{\mathrm{br}}$ were determined.

For the wave amplitude, the most likely value is taken either as the cited wave amplitude or as half the significant wave height measured (i.e. $a=H_{\mathrm{s}} / 2$ ). For the wave period, if no specific period is provided, the (local) peak period is taken. For all direct observations of wave amplitude and wave period an uncertainty of $10 \%$ is taken into account as the outer value of the triangular distribution, while for visual observations we use a larger uncertainty (case-specific and dependent on the absolute values of the variables). Based on the water depth, either estimated or provided, the wavelength is calculated following the linear dispersion relation. The impact of the ice on the wavelength (i.e. the flexural, compressive and ice added mass terms in the dispersion relation as expressed by for example Sutherland and Rabault, 2016) is assumed to be minor compared to the uncertainty included in the wave period. This is a reasonable assumption as most measurements have a wave period longer than 7 s (e.g. Sutherland and Rabault, 2016; Collins et al., 2018). As measurements of the ice thickness are expected to have higher uncertainty than the wave properties, an uncertainty of up to $50 \%$ is considered, but larger values are chosen for shipborne visual observations.

The mechanical properties of the ice have the largest uncertainty of all variables involved, in large part as they are difficult to measure, particularly in this extreme environment. Only in the studies of Marchenko et al. (2011, 2012, 2019) were the flexural strength $(\sigma)$ and/or Young's modulus $(Y)$ measured in situ, and they therefore provide the narrowest range of uncertainty. Note that in the case of the tsunami wave observations of Marchenko et al. (2012) details of the ice properties during this experiment are provided in Marchenko et al. (2013) and Karulina et al. (2019). For the Arctic field experiment (this study) and the observation of Asplin et al. (2012) only ice salinity and temperature were 
measured. For these experiments we approximate $\sigma$ and $Y$ through their strong dependence on brine volume. Using the empirical relation of Frankenstein and Garner (1967), the brine volume can be approximated by

$v_{\mathrm{b}}=S_{\text {ice }}\left(\frac{49.185}{\left|T_{\text {ice }}\right|}+0.532\right)$,

where $v_{\mathrm{b}}$ is the brine volume fraction, $S_{\text {ice }}$ is the ice salinity (fraction) and $T_{\text {ice }}$ is the ice temperature in degrees Celsius. This gives an estimated sea ice brine volume of 4.51 and $6.66 \%$ during our Arctic experiment and the study of Asplin et al. (2012), respectively. As sea ice properties are strongly influenced by the conditions of its formation and development, the empirical relations for sea ice properties in terms of brine volume are considered to be region-specific (Karulina et al., 2019). Hence, for our Arctic field experiment we consider empirical relations from the study of Karulina et al. (2019), which is focused on the ice properties in the Svalbard archipelago, yielding

$\sigma=0.5266 \exp \left(-2.804 \sqrt{v_{\mathrm{b}}}\right)$,

$Y=3.1031 \exp \left(-3.385 \sqrt{v_{\mathrm{b}}}\right)$.

The scatter of data for $\sigma$ and $Y$ in Karulina et al. (2019) is used to quantify the uncertainty. For the sea ice break-up observation of Asplin et al. (2012) we use the commonly used empirical relation of Timco and O'Brien (1994) instead to approximate the flexural strength:

$\sigma=1.76 \exp \left(-5.88 \sqrt{v_{\mathrm{b}}}\right)$.

For Young's modulus we consider the empirical relation of Vaudrey (1977):

$Y=5.31-0.436 \sqrt{1000 v_{\mathrm{b}}}$.

It is worth mentioning that the value for $\sigma$ calculated following this approach in Asplin et al. (2012) is incorrect due to a typographical error in their equation (compare Eq. 8 here to their Eq. 4). An uncertainty of $50 \%$ is assigned to $\sigma$ and $Y$ for the observation of Asplin et al. (2012).

For all other observations where no details of sea ice properties were measured or provided, we assign a relatively conservative range of uncertainty to $\sigma$ and $Y$. For experiments within the Svalbard archipelago, we choose a range of $\sigma \in[0.109,0.415] \mathrm{MPa}$ and $Y \in[0.4,3] \mathrm{GPa}$ with most probable values of $\sigma=2.62 \mathrm{MPa}$ and $Y=1.25 \mathrm{GPa}$ (Karulina et al., 2019). A wider range for $\sigma$ and $Y$ is expected to be found elsewhere, and, as such, we expand the uncertainty for observations made in other regions given by $\sigma \in[0.1,0.7] \mathrm{MPa}$ and $Y \in[1,6] \mathrm{GPa}$ with most probable values of $\sigma=0.4 \mathrm{MPa}$ and $Y=3$. A summary of all data used and their estimated uncertainty is provided in Table 1.

\section{Results}

\subsection{Antarctic deployment}

The first break-up event observed during the Antarctic campaign occurred about 3 weeks after instrument deployment. Based on satellite images, it can be observed that between 2 and 3 January 2020 a giant ice floe (approximately $20 \mathrm{~km} \times 10 \mathrm{~km}$ in size) broke from the fast ice (see Fig. 3). Based on the sudden change in geographical location of all four instruments (not shown here), this occurred around 1 January 2020 at 18:00 UTC. It also shows that all instruments are located on this giant ice floe which drifted at an average speed of approximately $0.03 \mathrm{~m} \mathrm{~s}^{-1}$ after the initial break-up. Note that on the satellite images of 3 and 4 January 2020 multiple cracks can be observed (see arrow in Fig. 3). Unfortunately, clouds in the days after prevent us from monitoring the ice conditions in the days that followed.

As all instruments transmit their geographical location at regular intervals, albeit at different times, we can identify the occurrence of sea ice break-up and approximate the times at which these events occurred through the monitoring of sudden changes in the relative distance between buoy pairs $\Delta x$ during the deployment (see Fig. 4). In all the following, the distance $\Delta x$ is relative to the distance at the time of deployment; i.e. initially $\Delta x$ is taken equal to 0 , and any change in $\Delta x$ is due to relative motion of the instruments. However, for brevity, we will refer to this quantity as the "distance" between the instruments.

As the geographical coordinates of the instruments are not transmitted at the same time and interval, we linearly interpolate the latitude and longitude coordinates to match between buoy pairs. As the ice floe upon which the instruments rest drifts, interpolation of the geographical location introduces a maximum error of typical magnitude $|\delta| \approx\left(\Delta t^{2} / 8\right) \max \left|\Delta x^{\prime \prime}(t)\right|$, where $\Delta t$ is the data transmission interval. The estimated value of the error $\delta$ is indicated by the horizontal dashed lines in Fig. 4. Before the first sea ice break-up event, the approximate maximum error of $\Delta x$ is $5 \mathrm{~m}$, a result of the accuracy of the GPS units when kept stationary during the initial 3 weeks of the deployment. From the instant at which the giant ice floe breaks from the ice cover and starts drifting (2 January 2020 at 18:00), the error increases to typically $\delta=16 \mathrm{~m}$. Note that the distance between all buoy pairs remains constant just after the separation event of the giant ice floe, as all instruments remain on the one ice floe. Also note that the accuracy of the distance between the two wave buoys is considerably better than with other buoy pairs as the data transmission interval $\Delta t$ is considerably smaller for the wave buoys than for the ice buoys.

After the giant ice floe separates from the ice cover and starts drifting, the next break-up event is thought to occur around 3 January 2020 at 21:00, where the distance between IB2 and the other three buoys instantly increases to a distance of $60-70 \mathrm{~m}$ (Fig. 4). This is in line with the satellite 


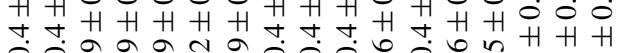

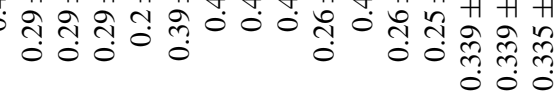

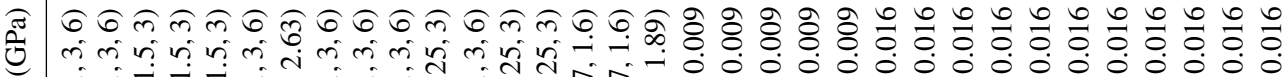

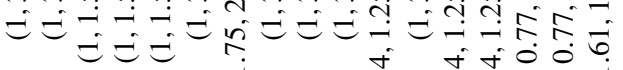

$$
\begin{aligned}
& \begin{array}{c}
\vec{\infty} \\
\infty \\
\infty \\
0
\end{array}
\end{aligned}
$$

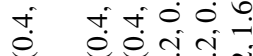

สุ $\therefore-H+H+H$ in $i$

चं

$\stackrel{m}{\varrho} \stackrel{m}{e}$

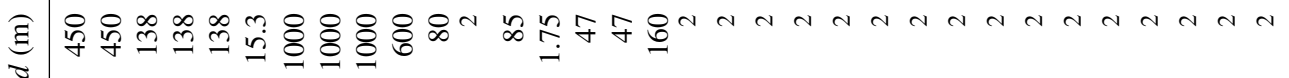

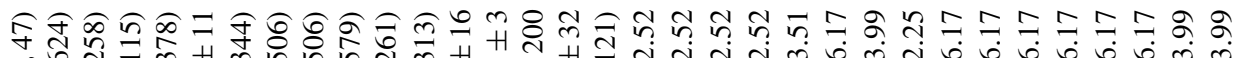

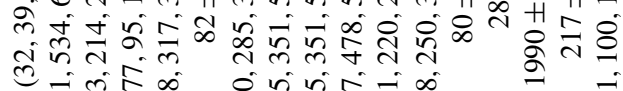

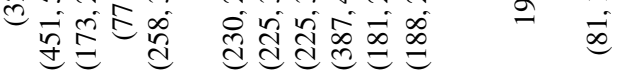

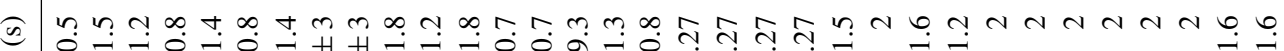

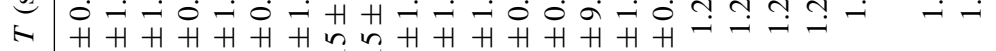

in $n=\infty, \infty, \infty$ in

$\stackrel{g}{g}$

$\ddot{\nabla}$

可 б

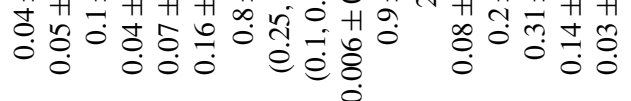

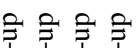

₹ :

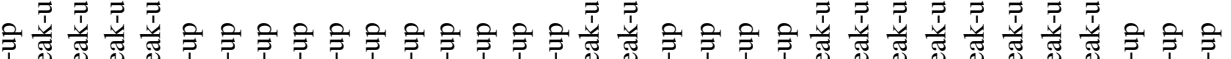

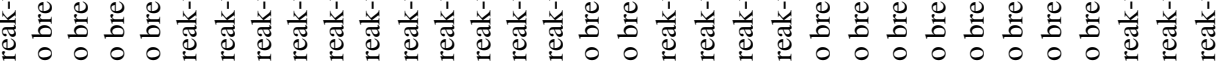
点

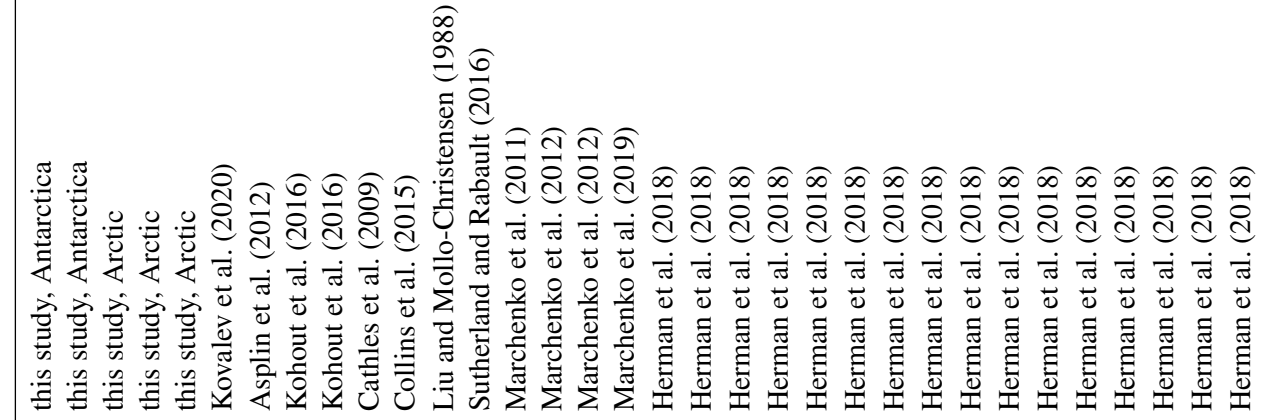

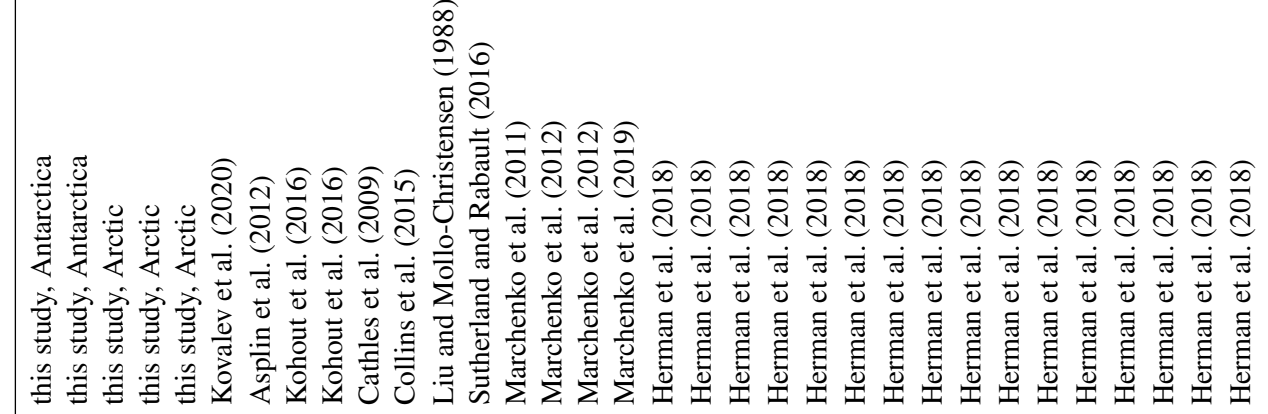

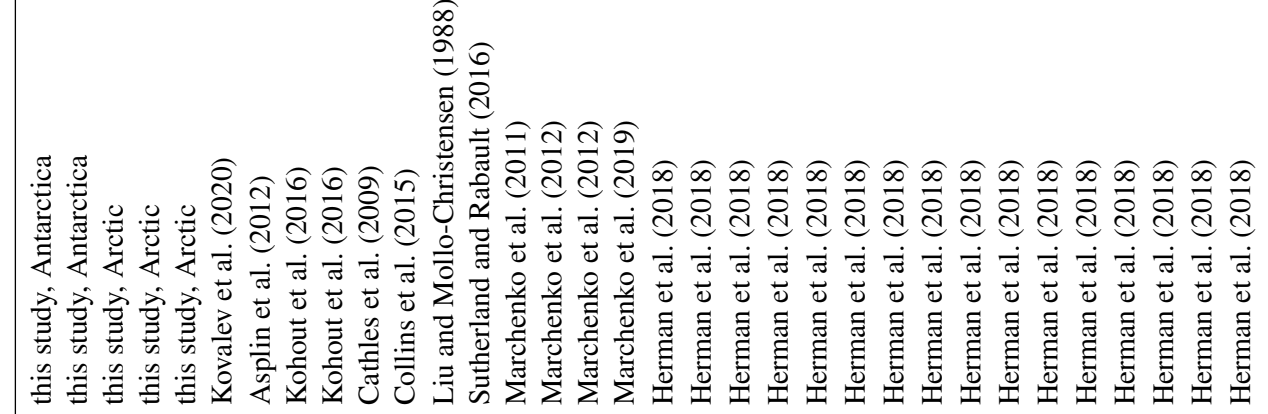

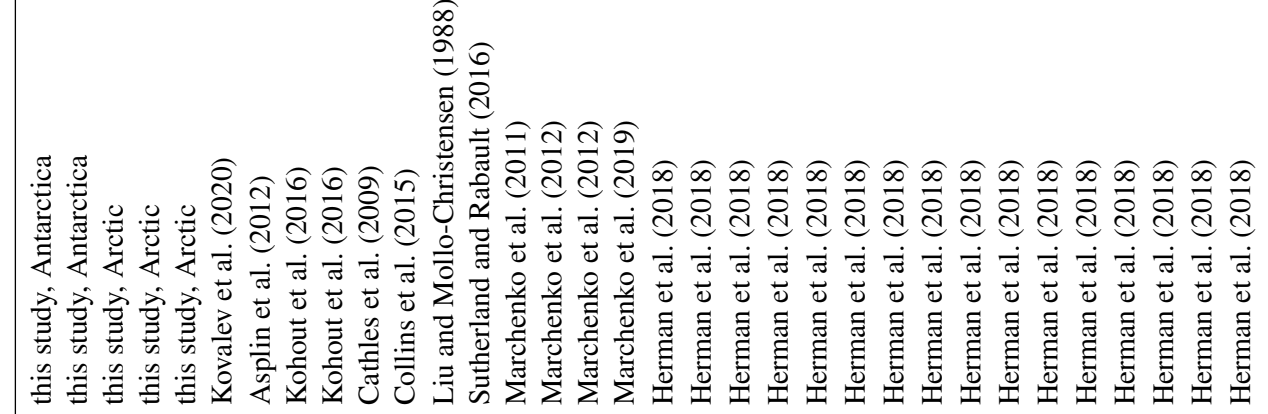



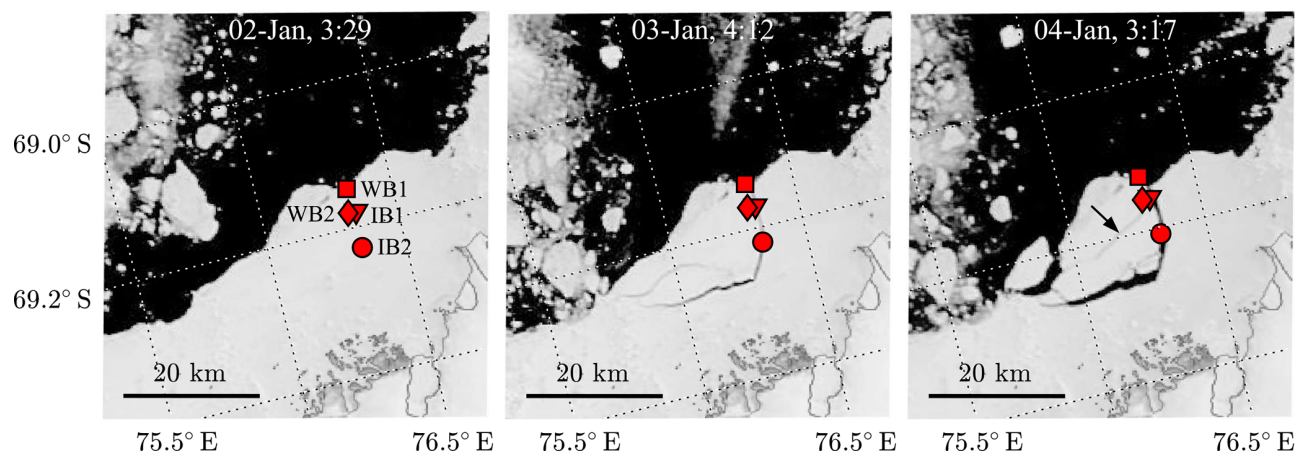

Figure 3. MODIS imagery (https://worldview.earthdata.nasa.gov/, last access: 12 March 2020) of the Antarctic deployment site on 3 consecutive cloud-free days during the initial sea ice break-up. Instruments are indicated by markers: WB1 (square), WB2 (diamond), IB1 (triangle) and IB2 (circle). Note that the marker of IB1 is shifted here for visualization purposes and that IB1 was originally deployed $40 \mathrm{~m}$ from WB2.

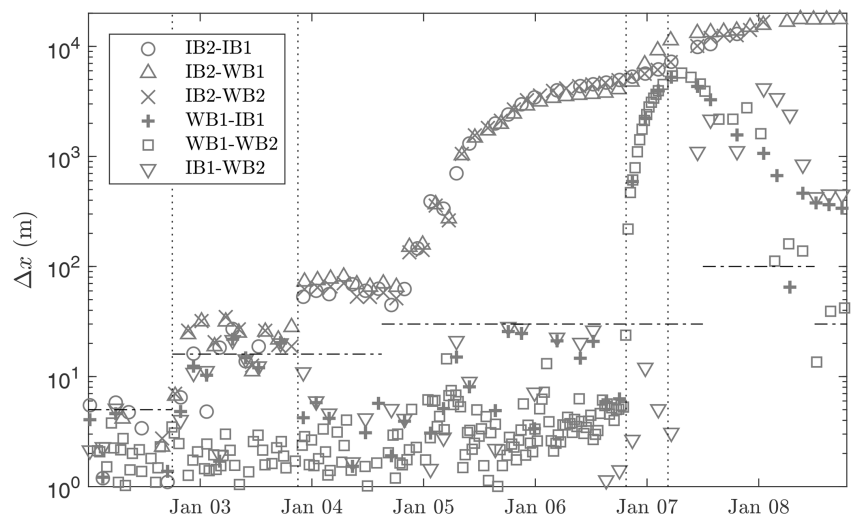

Figure 4. Distance $\Delta x$ between instruments relative to their distance at the time of deployment; i.e. $\Delta x$ is taken initially equal to 0 , and any change to $\Delta x$ indicates relative motion between the instruments. Vertical dashed lines indicate instances of sea ice break-up: (2 January 2020 at 18:00) all instruments start drifting due to breakup of large ice mass; (3 January 2020 at 21:00) IB2 separates from the large ice mass (see also Fig. 3c); (6 January 2020 at 19:30) WB1 splits from WB2 and IB1; (7 January 2020 at 04:30) the ice floe holding WB2 and IB1 breaks due to waves generated by the storm depicted in Fig. 2b. Horizontal dashed lines refer to the uncertainty level induced by GPS accuracy and interpolation error, where the latter increases with the drift speed of the instruments.

imagery (Fig. 3), where on 3 January 2020 the crack does not seem to have propagated all the way eastward, whereas on 4 January 2020 the crack seems to have split the giant ice floe completely (see the arrow in Fig. 3). It is not until 5 January 2020 that the distance between IB2 and the other instruments increases further. The third break-up event occurred around 6 January 2020 at 19:30, where the northernmost deployed instrument, WB1, splits from WB2 and IB1 (Fig. 3). This is followed shortly after by a fourth break-up event occurring around 7 January 2020 at 04:30 where the distance between WB2 and IB1 increases to about a kilometre within just $3 \mathrm{~h}$.
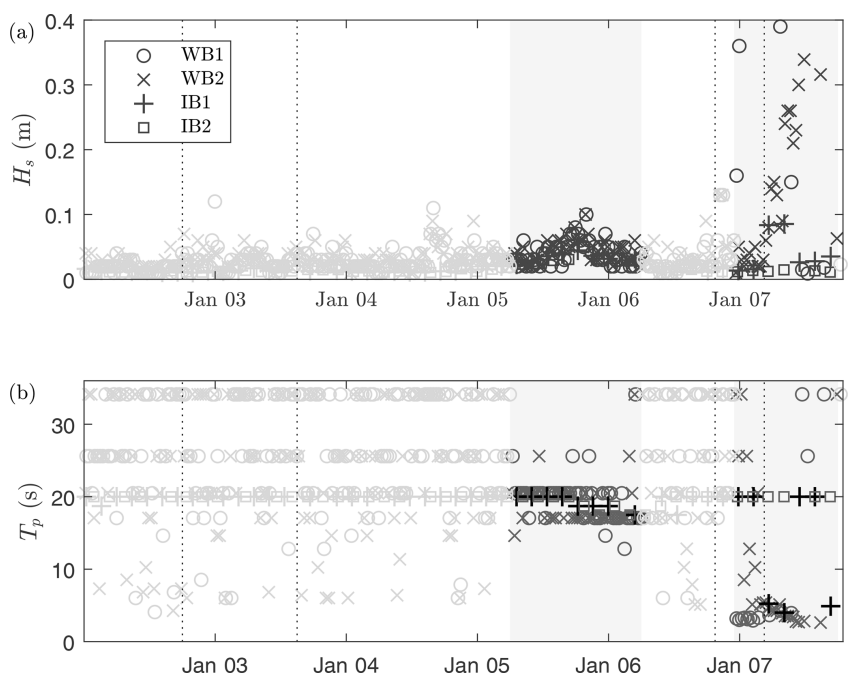

Figure 5. (a) Significant wave height and (b) peak period measured by the four instruments during the break-up of the Antarctic fast sea ice cover. Based on consistency of the measured peak period between all instruments, two sections contain reliable wave measurements over noise thresholds, corresponding to a swell event with maximum ice motion obtained on 5 January 2020 at 18:00 and wind waves just after 7 January 2020. These sections correspond to the grey areas and dark markers. Note that the vertical dashed lines indicate sea ice break-up events, extracted from Fig. 4.

To determine whether these break-up events were caused by wave-induced flexural motion, they are compared against the wave motions recorded by the instruments. Figure 5 shows the significant wave height and peak wave period measured by the instruments over a duration of $6 \mathrm{~d}$ after the initial breakaway of the giant ice floe. Note that up to $5 \mathrm{Jan}-$ uary 2020 the instruments do no provide reliable wave information as recorded motions are below the noise threshold of the instruments. While this can be observed indirectly from the transmitted $H_{\mathrm{s}}$ and $T_{\mathrm{p}}$, for the ice buoys this is confirmed through observation of the wave energy spectra, showing a 

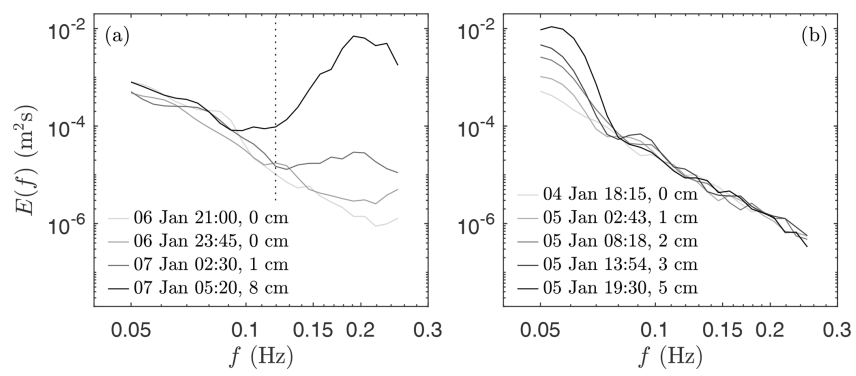

Figure 6. Wave energy spectra measured by (a) IB1 during the fourth identified sea ice break-up event and (b) IB2 during a swell event without sea ice break-up. The significant wave height of the spectra is provided in the legend; note that for (a) only the highfrequency part (i.e. $f>0.13$ ) of the spectrum is considered (see dashed line). The spectra obtained on 6 January 2020 at 21:00 (a) and 4 January 2020 at 18:15 (b) correspond to the noise level of the IMU. Both the measured wind waves in (a) and swell in (b) are well above noise levels. Note that in (a) energy in the high-frequency part of the spectrum increases substantially after ice break-up, which is estimated to take place around 7 January at 04:30.

linear energy decay in log scale from low to high frequencies, which corresponds to the noise threshold of the IMU (Rabault et al., 2020). There are, however, two clear instances of coherent measurements of both the peak period and wave height; see the shaded areas in Fig. 5.

For the first break-up event on 2 January 2020, no waves were measured above the noise level of the instruments, and the cause of the breakaway of the giant ice floe remains speculative. ERA5 re-analysis data just north of the northernmost sea ice edge indicate the presence of a $3 \mathrm{~m}$ swell a few hours preceding the break-up (generated by the storm depicted in Fig. 2a), and, as such, the swell might have been a potential cause of the break-up. However, as no significant ice motion events were recorded during this period of time by the instruments, it suggests that this swell event was largely dissipated by the vast sea ice band in front of the polynya. As there are no reliable wave measurements for the second and third break-up events either, we can only speculate about the cause of these events as well. As a few large cracks in the giant ice floe are already visible on 3 January 2020 (Fig. 3), therefore, it is most likely that the second break-up event was initiated at the same instant at which the giant ice floe broke from the fast ice cover. The third break-up event, however, is most likely induced by waves generated by the more energetic storm passing the deployment site during this part of the deployment (Fig. 2b).

Unlike the first three break-up events, wave motions above noise thresholds were measured during the fourth sea ice break-up event. In particular, this break-up event coincides with the passage of the low-pressure system and the presence of high wind speeds of about $10-15 \mathrm{~m} \mathrm{~s}^{-1}$ over and aligned with the main axis of the polynya region (based on ERA5; see Fig. 2b). With an area of approximately $100 \mathrm{~km} \times 300 \mathrm{~km}$, the polynya provide sufficient fetch for the waves to develop. Around the time of break-up, a consistent peak wave period of around $5 \mathrm{~s}$ is measured by WB2 and, to lesser extent, by IB1. The wave energy spectra measured by WB2, however, show that the wave energy in the high-frequency range (around $f=0.2 \mathrm{~Hz}$ ) increases steadily with time (Fig. 6a). This explains the sudden change in $T_{\mathrm{p}}$ for IB 1 : the noise level at the lowest resolved frequency is larger than the measured wave energy in the high-frequency range, so the wave amplitude of the relatively high-frequency waves has to reach a threshold before it is considered as the peak wave frequency $T_{\mathrm{p}}$.

The significant wave height of the high-frequency waves (that is, when considering the wave energy for $f>0.12 \mathrm{~Hz}$ ) is only $0.01 \mathrm{~m}$ at $02: 30$ on 7 January 2020 , and $0.08 \mathrm{~m}$ at 05:20. This suggests that the fourth break-up event, occurring around 04:30, was induced by waves with period of approximately $5 \mathrm{~s}$, with an estimated wave height of around $0.04 \mathrm{~m}$. It is noteworthy that the wave buoy WB1, which separated from WB2 and IB1 during the third break-up event, measured a significant wave height of up to $0.4 \mathrm{~m}$ at the time of the fourth break-up event, also with a period of approximately $4-5 \mathrm{~s}$, indicating that the energetic wind waves were generated locally (since, if generated in the Southern Ocean, these waves would have dissipated rapidly in the sea ice band north of the polynya).

Besides this wave-induced break-up event, a distinct swell event around 5 January 2020 at 18:00 was measured by all four instruments (Fig. 5), though, it did not lead to sea ice break-up. From the spectra measured by the ice buoys it can be seen that the observed wave energy is comfortably above instrument noise level (Fig. 6b). The time frame of this swell event corresponds well to the passage of a storm moving north-east at this instant. This swell event will be used as a non-break-up event with a significant wave height of $0.05 \mathrm{~m}$ and period $T=17-20$ s (Figs. 5 and $6 \mathrm{~b}$ ).

\subsection{Arctic experiment}

During the Arctic field campaign, no sea ice break-up was observed and all instruments remained stationary during the deployment. The measurements of significant wave height and peak wave period are shown in Fig. 7. Three distinct wave events are considered as ice motion observations without sea ice break-up. The events have a peak period $T_{\mathrm{p}}=$ 7.8, 11.7 and $14.3 \mathrm{~s}$, and corresponding wave heights are $H_{\mathrm{s}}=0.04,0.10$ and $0.07 \mathrm{~m}$, respectively (see dashed lines in Fig. 7).

\subsection{Ice break-up threshold}

Combining the break-up and non-break-up events obtained during the two field campaigns, and the set of existing published observations, the ice break-up parameter $I_{\text {br }}$ can be determined (see results in Fig. 8). In Fig. 8, we plotted $I_{\mathrm{br}}$ 


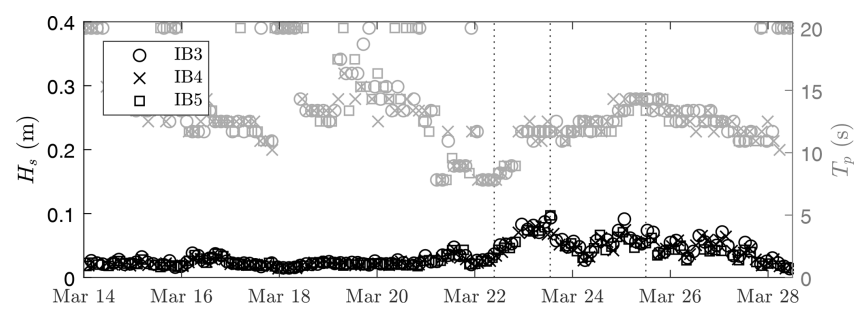

Figure 7. Significant wave height and peak period measured by three ice buoys deployed on fast ice in Svalbard. The dashed lines identify three events with distinct peak wave period and peak significant wave height.

against the relative ice thickness $h / \lambda$ to separate between ice breaking and non-breaking observations. Note that the red markers identify events where the ice remained intact under the wave motion. We reiterate that, similarly but contrapositive for the unbroken ice events, observations of sea ice break-up define a sufficient condition for wave-induced sea ice break-up, not the absolute threshold for the break-up parameter $I_{\mathrm{br}}$. It is seen that broken and unbroken observations can be reasonably separated by a constant value of $I_{\mathrm{br}}$. Therefore, based on the data presented in Fig. 8, we find the critical value of $I_{\mathrm{br}}$ to be equal to

$I_{\mathrm{br}} \approx 0.014$

While this threshold is most accurately defined by the laboratory experiments of Herman et al. (2018) (particularly as these constitute about half of the points in the data set), observations obtained in the field are well aligned with this threshold too. Note that, while one of the shipborne break-up observations of Kohout et al. (2016) falls below this threshold, the large uncertainty of this particular visual observation covers both sides of the critical threshold.

\section{Discussion}

In the present work, we have collected experimental observations, both from the laboratory and from the field, displaying both wave-induced sea ice break-up events and waveinduced ice motion events without break-up. Thereafter, we have used these data to estimate the critical threshold value for the wave-induced sea ice break-up parameter $I_{\mathrm{br}}$. We find that observations consistently point to a constant value of $I_{\mathrm{br}}$, which we estimate to be $I_{\text {br }} \approx 0.014$ (see Fig. 8). Note, however, as we can only measure statistical wave properties in an incoherent wave field, and thus $I_{\mathrm{br}}$ is a probabilistic metric rather than a deterministic metric, the threshold observed in this study therefore suggests that above $I_{\mathrm{br}}=0.014$ the ice is very likely (but not necessarily) going to break. Though the data set is still rather limited, it is promising that both field and laboratory observations are well aligned with this critical value. In particular, laboratory-grown ice is known to have distinctly different material properties (e.g. Herman et al., 2018; Squire, 2020); for instance, the ice in the laboratory data used here has a critical strain 1-2 orders of magnitude larger than that of sea ice in the field. Interestingly, the swellinduced crack propagation of the Ross Ice Shelf, as implied by Cathles et al. (2009), seems to fit well within the overall data set, indicating that it might be possible to extrapolate the wave-induced sea ice break-up criterion to much thicker ice covers as well.

While we observe that the critical value determined in this study is 3-4 times smaller than that of a monochromatic wave (e.g. Williams et al., 2013a), this value is remarkably similar to that proposed by Boutin et al. (2018), who argued, based on statistical considerations, that a factor of 3.6 should be used to take into account the random nature of the wave field and the resulting stochastic distribution in individual wave amplitudes. However, as the ice in the laboratory experiments of Herman et al. (2018) was exposed to monochromatic waves, rather than a random wave field, it remains uncertain whether this factor is indeed a statistical correction; a compensation for the simplification of the sea ice material properties (that is, by ignoring fatigue and the presence of sea ice heterogeneities, the critical flexural strength of the ice is effectively lower than those values used here); or, more likely, a combination of both. This emphasizes the difficulty in assigning a single characteristic wavelength to a break-up event for a wave field that is inherently random and consists of a range of length scales. Nevertheless, as short waves dissipate rapidly near the ice edge, the spectrum is often narrow-banded, and thus the peak period is likely to be the most representative scale to characterize a break-up event. Either way, our experimental results are in support of the current approaches developed to model the break-up of a solid ice cover under wave forcing in coupled numerical models, although further study is required to understand the finer details of the physics behind wave-induced sea ice break-up.

Although the wave-induced sea ice break-up parameter $I_{\mathrm{br}}$ seems to be physically sound, the scaling of $I_{\mathrm{br}} \propto h$ is problematic when the ice material properties $Y$ and $\sigma$ remain virtually unchanged when thin ice is considered; that is, an infinitely thin ice sheet becomes numerically unbreakable (as noted in The WAVEWATCH III Development Group, 2019). However, for small ice thicknesses, other physical processes may be naturally dominant, such as compressive or tensile failure of the ice through wind and ocean current shear forces. Indeed, the relative effect of such forcing scales inversely to the ice thickness (e.g. Mellor, 1986), contrary to what is obtained with the present expression for $I_{\mathrm{br}}$. This highlights that waves and sea ice are part of a complex coupled system at the interface of the atmosphere and ocean, and that many different physical phenomena influence sea ice dynamics. Waves can, however, still play a critical role in the break-up of thin ice. For instance, thick ice attenuates wave energy more strongly than thin ice (e.g. Doble 


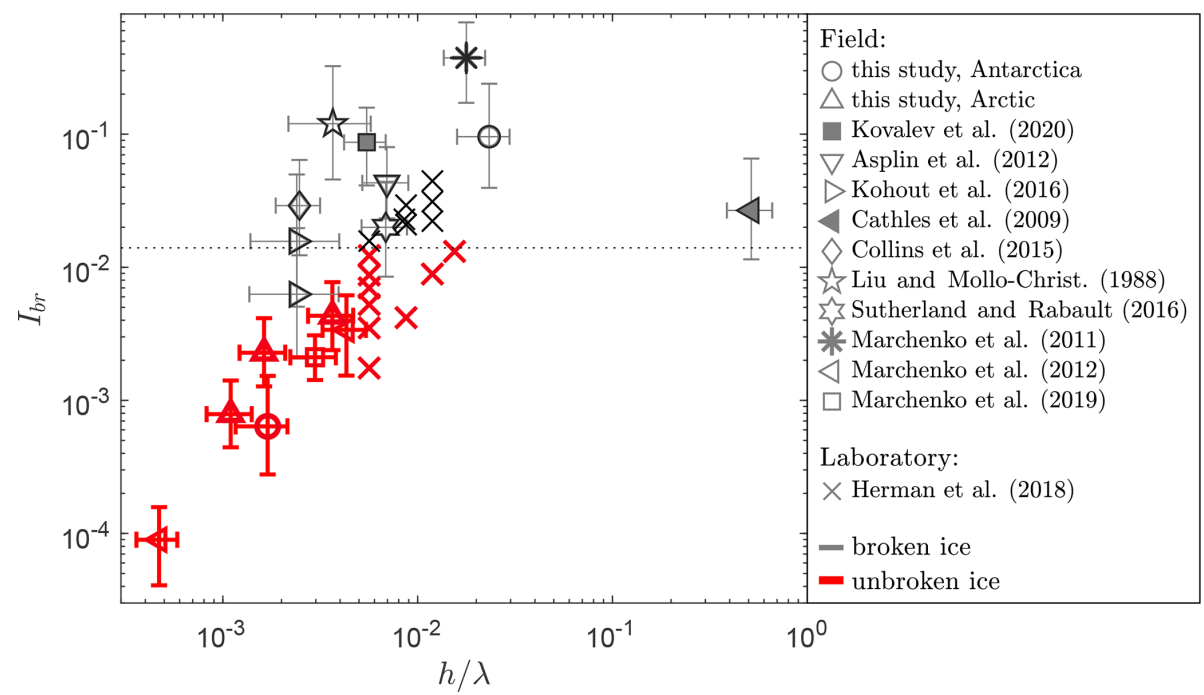

Figure 8. Observations of $I_{\mathrm{br}}$ against the relative ice thickness $h / \lambda$ for the complete data set. Events of wave-induced sea ice break-up are indicated with black markers, whereas observations where the flexural motion did not lead to break-up of the sea ice are shown with red markers. The observational threshold value $I_{\mathrm{br}} \approx 0.014$, which separates the break-up from the non-break-up events, is indicated by the dashed line.

et al., 2015; Meylan et al., 2018; Liu et al., 2020), therefore, thin ice is generally exposed to more wave energy, including shorter wavelengths. Moreover, there are still significant uncertainties in the actual mechanical properties of very thin ice relative to thicker ice. Fast-grown thin ice (for instance, in the case of very cold air temperature) has a lower flexural strength compared to slow-grown ice (Bond and Langhorne, 1997), which the literature claims to be caused by its higher bulk salinity (Perovich and Richter-Menge, 1994). Moreover, Kovacs (1996) finds that the salinity of young ice decreases with increasing ice thickness, implying that thin ice might be consistently weaker than thicker ice following Eqs. (6) and (8). As ice properties can vary significantly in time, more studies are required to accurately measure and define the mechanical properties of sea ice in terms of more readily available air-sea ice properties, and the role of ice inhomogeneities caused by bubbles and brine pockets, ice ridges, pools, and ice thickness variability needs to be further investigated.

While the current definition of $I_{\mathrm{br}}$ suggests that very short waves always break the ice, it is worth reiterating that the assumption underlying Eq. (2) is that the ice is considered to be thin with respect to the wavelength (i.e. $h / \lambda \ll 1$ ) and elastic, implying that the ice moves compliantly with the sea surface. Thus, the threshold of $I_{\mathrm{br}}$ defined in this study does not necessarily hold for short waves or, strictly speaking, for $h / \lambda \gg 1$. While the exact range of $h / \lambda$ for which the observed threshold of $I_{\mathrm{br}}$ is valid is uncertain; based on the observations presented here (Fig. 8), it seems that it holds up for $h / \lambda<0.02$. More observations are required to clarify its validity for $h / \lambda=O(0.1-1)$. This is, however, not necessarily a limitation of the parameterization of $I_{\mathrm{br}}$ as short waves are, in general, attenuated rapidly when entering the ice cover due to wave energy dissipation and scattering.

Field observations of waves, ice motion, ice material properties and sea ice break-up identification bring unavoidable uncertainties, resulting in a significant uncertainty for $I_{\mathrm{br}}$. Particularly the mechanical properties of sea ice are uncertain due to the validity of the experimental methods used (e.g. see Timco and Weeks, 2010; Karulin et al., 2019), fatigue (e.g. Langhorne et al., 1998), spatial heterogeneity at various scales and even questions regarding the scaling effects of the ice flexural strength (Aly et al., 2019). Identifying the instant at which the ice breaks creates an additional uncertainty. The method which consists in identifying the instant of sea ice break-up through the spatial divergence of instrumentation, as applied in this study, is not foolproof by itself. In fact, if the ice floes do not drift apart after break-up, the relative distance between instruments will not change. As the sea ice in our field experiments was drifting during break-up, it is expected that the resulting ice floes after break-up will attain a different drift speed. In the case of the Antarctic field campaign, the instruments drifted at a speed of $0.03-0.20 \mathrm{~m} \mathrm{~s}^{-1}$; even if the differential drift between floes immediately after break-up is only a fraction of this drift speed, this will be noticed from the position of the instruments within hours of the time of break-up, at most.

Overall, a dedicated field experiment, with the aim to closely monitor both the mechanical properties of the ice and the exact instant at which the ice breaks, is highly desirable and is expected to provide further clarification over the accuracy of the observed threshold for $I_{\mathrm{br}}$ reported here. Until then, many more observations of wave-induced ice motion leading up to ice break-up are necessary to further sub- 
stantiate the wave-induced break-up parameter and its critical threshold. Evidently, development of low-cost and opensource instrumentation is critical in obtaining a large data set of break-up observations, as it promotes the deployment of ice buoys in larger quantities and, therefore, allows for dramatic increase in the overall volume of data reporting the interactions between sea ice, waves, the atmosphere and the ocean.

\section{Conclusions}

We presented observations of wave-induced ice motion and sea ice break-up events from two field experiments, one in the Antarctic and the other in the Arctic. Using the relative displacement between the instruments deployed, four sea ice break-up events were registered in the Antarctic field experiment, although only one could, with reasonably certainty, be linked to waves. While no sea ice break-up events were observed in the Arctic field experiments, it provided three wave events without sea ice break-up. We used these observations, supplemented with existing data taken from a wide body of the literature, to reach an estimate for the critical threshold of the wave-induced sea ice break-up parameter $I_{\mathrm{br}}=$ $a h Y / \sigma \lambda^{2}$, where $a$ is the wave amplitude, $h$ is the ice thickness, $Y$ is Young's modulus, $\sigma$ is the ice flexural strength and $\lambda$ is the wavelength. We find that a value $I_{\mathrm{br}}=0.014 \mathrm{sep}$ arates well observations of wave-induced break-up and non break-up events. Observations include laboratory measurements, as well as suspected cracking of the Ross Ice Shelf. The physical relevance of $I_{\mathrm{br}}$ is substantiated by the diversity of cases present in the data, from laboratory to the field, the Antarctic to the Arctic and thin ice to very thick ice. However, significantly more observations of sea ice break-up are necessary, and, perhaps, more sophisticated measurement techniques need to be developed in order to identify the exact instant at which break-up occurs and the wave conditions responsible for the observed sea ice break-up.

$\begin{aligned} & \text { Data availability. Data } \\ & \text { able through the Australian }\end{aligned}$ be made
tre antarctic Data Cen-
(https://doi.org/10.4225/15/590173acc61c9, Voermans, 2020).

Author contributions. JJV and AVB conceptualized the study. JJV and JR built instrumentation. KF and IR deployed and retrieved instrumentation. MD and GS assisted in satellite imagery. AVB and AM administered the project. JJV and JR prepared the original draft. All authors reviewed and edited the manuscript.

Competing interests. The authors declare that they have no conflict of interest.
Acknowledgements. We acknowledge the use of imagery from the NASA Worldview application (https://worldview.earthdata.nasa. gov/, last access: 12 March 2020), part of the NASA Earth Observing System Data and Information System (EOSDIS). Authors would like to thank the crew of AARI for their assistance during the deployment of the instruments used in the Antarctic. We thank Atle Jensen and Olav Gundersen for their support in assembling IB1 and IB2 (IB3, IB4 and IB5 were assembled at Melbourne University following the same design). Data collection in Grønfjorden, Svalbard, was conducted within the expedition "Spitsbergen-2020" organized by the Russian Scientific Arctic Expedition on Spitsbergen Archipelago (RAE-S), AARI. Joey J. Voermans and Alexander V. Babanin acknowledge support from the Joyce Lambert Antarctic Research Fund (grant no. 604086). Joey J. Voermans, Alexander V. Babanin and Petra Heil were supported by the Australian Antarctic Program under project 4593, and Petra Heil under project 4506. Joey J. Voermans, Jean Rabault, Kirill Filchuk, Aleksey Marchenko and Alexander V. Babanin acknowledge the support of the Research Council of Norway through the SFI SIB project. Jean Rabault was supported in the context of the DOFI project (University of Oslo, grant no. 280625). The authors would like to thank the two anonymous reviewers for their comments and feedback on the manuscript.

Financial support. This research has been supported by the Joyce Lambert Antarctic Research Fund (grant no. 604086), the Australian Antarctic Program (grant no. 4593), the Australian Antarctic Program (grant no. 4506), the Research Council of Norway (SFI SIB grant) and the University of Oslo (DOFI project, grant no. 280625).

Review statement. This paper was edited by Yevgeny Aksenov and reviewed by two anonymous referees.

\section{References}

Aly, M., Taylor, R., Bailey Dudley, E., and Turnbull, I.: Scale Effect in Ice Flexural Strength, J. Offshore Mech. Arct., 141, 051501, https://doi.org/10.1115/1.4042388, 2019.

Ardhuin, F., Boutin, G., Stopa, J., Girard-Ardhuin, F., Melsheimer, C., Thomson, J., Kohout, A., Doble, M., and Wadhams, P.: Wave attenuation through an arctic marginal ice zone on 12 October 2015: 2. Numerical modeling of waves and associated ice breakup, J. Geophys. Res.-Oceans, 123, 5652-5668, 2018.

Asplin, M. G., Galley, R., Barber, D. G., and Prinsenberg, S.: Fracture of summer perennial sea ice by ocean swell as a result of Arctic storms, J. Geophys. Res.-Oceans, 117, C06025, https://doi.org/10.1029/2011JC007221, 2012.

Bond, P. E. and Langhorne, P. J.: Fatigue behavior of cantilever beams of saline ice, J. Cold. Reg. Eng., 11, 99-112, 1997.

Boutin, G., Ardhuin, F., Dumont, D., Sévigny, C., Girard-Ardhuin, F., and Accensi, M.: Floe Size Effect on Wave-Ice Interactions: Possible Effects, Implementation in Wave Model, and Evaluation, J. Geophys. Res.-Oceans, 123, 4779-4805, 2018.

Boutin, G., Lique, C., Ardhuin, F., Rousset, C., Talandier, C., Accensi, M., and Girard-Ardhuin, F.: Towards a coupled model to investigate wave-sea ice interactions in the Arctic marginal ice 
zone, The Cryosphere, 14, 709-735, https://doi.org/10.5194/tc14-709-2020, 2020.

Bromirski, P. D., Sergienko, O. V., and MacAyeal, D. R.: Transoceanic infragravity waves impacting Antarctic ice shelves, Geophys. Res. Lett., 37, L02502, https://doi.org/10.1029/2009GL041488, 2010.

Buckingham, E.: On physically similar systems; illustrations of the use of dimensional equations, Phys. Rev., 4, 345, https://doi.org/10.1103/PhysRev.4.345, 1914.

Cathles, L., Okal, E. A., and MacAyeal, D. R.: Seismic observations of sea swell on the floating Ross Ice Shelf, Antarctica, J. Geophys. Res.-Earth, 114, F02015, https://doi.org/10.1029/2007JF000934, 2009.

Collins, C., Doble, M., Lund, B., and Smith, M.: Observations of surface wave dispersion in the marginal ice zone, J. Geophys. Res.-Oceans, 123, 3336-3354, 2018.

Collins, C. O., Rogers, W. E., Marchenko, A., and Babanin, A. V.: In situ measurements of an energetic wave event in the Arctic marginal ice zone, Geophys. Res. Lett., 42, 1863-1870, 2015.

Crocker, G. and Wadhams, P.: Breakup of Antarctic fast ice, Cold Reg. Sci. Technol., 17, 61-76, 1989.

Doble, M. J., De Carolis, G., Meylan, M. H., Bidlot, J.-R., and Wadhams, P.: Relating wave attenuation to pancake ice thickness, using field measurements and model results, Geophys. Res. Lett., 42, 4473-4481, 2015.

Dumont, D., Kohout, A., and Bertino, L.: A wave-based model for the marginal ice zone including a floe breaking parameterization, J. Geophys. Res.-Oceans, 116, C04001, https://doi.org/10.1029/2010JC006682, 2011.

Frankenstein, G. and Garner, R.: Equations for determining the brine volume of sea ice from $-0.5^{\circ}$ to $-22.9^{\circ}$ C., J. Glaciol., 6, 943-944, 1967.

Herman, A., Evers, K.-U., and Reimer, N.: Floe-size distributions in laboratory ice broken by waves, The Cryosphere, 12, 685-699, https://doi.org/10.5194/tc-12-685-2018, 2018.

Herman, A., Cheng, S., and Shen, H. H.: Wave energy attenuation in fields of colliding ice floes - Part 2: A laboratory case study, The Cryosphere, 13, 2901-2914, https://doi.org/10.5194/tc-13-29012019, 2019.

Horvat, C., Tziperman, E., and Campin, J.-M.: Interaction of sea ice floe size, ocean eddies, and sea ice melting, Geophys. Res. Lett., 43, 8083-8090, 2016.

Hwang, B., Wilkinson, J., Maksym, E., Graber, H. C., Schweiger, A., Horvat, C., Perovich, D. K., Arntsen, A. E., Stanton, T. P., Ren, J., and Wadhams, P.: Winter-to-summer transition of Arctic sea ice breakup and floe size distribution in the Beaufort Sea, Elem. Sci. Anth., 5, https://doi.org/10.1525/elementa.232, 2017.

Karulin, E. B., Marchenko, A. V., Sakharov, A. N., Karulina, M. M., Chistyakov, P. V., and Onishchenko, D. A.: Features of determining the ice flexural strength and the elastic modulus based on floating cantilever beam tests, in: Proceedings of the 25th International Conference on Port and Ocean Engineering under Arctic Conditions, 592, 9-13 June 2019, Delft, The Netherlands, 2019.

Karulina, M., Marchenko, A., Karulin, E., Sodhi, D., Sakharov, A., and Chistyakov, P.: Full-scale flexural strength of sea ice and freshwater ice in Spitsbergen Fjords and North-West Barents Sea, Appl. Ocean Res., 90, 101853, https://doi.org/10.1016/j.apor.2019.101853, 2019.
Kohout, A., Williams, M., Dean, S., and Meylan, M.: Storminduced sea-ice breakup and the implications for ice extent, Nature, 509, 604-607, 2014.

Kohout, A., Williams, M., Toyota, T., Lieser, J., and Hutchings, J.: In situ observations of wave-induced sea ice breakup, Deep Sea Res. Pt. II:, 131, 22-27, 2016.

Kohout, A. L. and Meylan, M. H.: An elastic plate model for wave attenuation and ice floe breaking in the marginal ice zone, J. Geophys. Res.-Oceans, 113, C09016, https://doi.org/10.1029/2007JC004434, 2008.

Kovacs, A.: Sea ice. Part 1. Bulk salinity versus ice floe thickness, Tech. rep., Cold Regions Research and Engineering lab Hanover, NH, 1996.

Kovalev, D. P., Kovalev, P. D., and Squirecor, V. A.: Crack formation and breakout of shore fast sea ice in Mordvinova Bay, southeast Sakhalin Island, Cold Reg. Sci. Technol., 175, 103082 , https://doi.org/10.1016/j.coldregions.2020.103082, 2020.

Langhorne, P. J., Squire, V. A., Fox, C., and Haskell, T. G.: Breakup of sea ice by ocean waves, Ann. Glaciol., 27, 438-442, 1998.

Liu, A. K. and Mollo-Christensen, E.: Wave propagation in a solid ice pack, J. Phys. Oceanogr., 18, 1702-1712, 1988.

Liu, Q., Rogers, W. E., Babanin, A., Li, J., and Guan, C.: Spectral modelling of ice-induced wave decay, J. Phys. Oceanogr., 50, 1583-1604, 2020.

Marchenko, A. and Cole, D.: Three physical mechanisms of wave energy dissipation in solid ice, in: Proceedings of the 24th International Conference on Port and Ocean Engineering under Arctic Conditions, 141-149, 11-16 June 2017, Busan, Korea, 2017.

Marchenko, A., Shestov, A., Karulin, E., Morozov, E., Karulina, M., Bogorodsky, P., Muzylev, S., Onishchenko, D., and Makshtas, A.: Field studies of sea water and ice properties in Svalbard fjords, in: Proceedings of the International Conference on Port and Ocean Engineering Under Arctic Conditions, POAC11-148, 10-14 July 2011, Montreal, Canada, 2011.

Marchenko, A., Morozov, E., and Muzylev, S.: Measurements of sea-ice flexural stiffness by pressure characteristics of flexuralgravity waves, Ann. Glaciol., 54, 51-60, 2013.

Marchenko, A., Wadhams, P., Collins, C., Rabault, J., and Chumakov, M.: Wave-ice interaction in the NorthWest Barents Sea, Appl. Ocean Res., 90, 101861, https://doi.org/10.1016/j.apor.2019.101861, 2019.

Marchenko, A. V., Morozov, E. G., and Muzylev, S. V.: A tsunami wave recorded near a glacier front, Nat. Hazards Earth Syst. Sci., 12, 415-419, https://doi.org/10.5194/nhess-12-415-2012, 2012.

Massom, R. A., Scambos, T. A., Bennetts, L. G., Reid, P., Squire, V. A., and Stammerjohn, S. E.: Antarctic ice shelf disintegration triggered by sea ice loss and ocean swell, Nature, 558, 383-389, 2018.

Mellor, M.: Mechanical behavior of sea ice, in: The geophysics of sea ice, Springer, 165-281, 1986.

Meylan, M. and Bennetts, L.: Three-dimensional time-domain scattering of waves in the marginal ice zone, Philos. T. R. Soc. A 376, 20170334, https://doi.org/10.1098/rsta.2017.0334, 2018.

Meylan, M. H., Bennetts, L. G., Mosig, J., Rogers, W., Doble, M., and Peter, M. A.: Dispersion relations, power laws, and energy loss for waves in the marginal ice zone, J. Geophys. Res.-Oceans, 123, 3322-3335, 2018.

Murdza, A., Schulson, E. M., and Renshaw, C. E.: Strengthening of columnar-grained freshwater ice through cyclic flexural loading, 
J. Glaciol., 66, 556-566, https://doi.org/10.1017/jog.2020.31, 2020.

Perovich, D. K. and Richter-Menge, J. A.: Surface characteristics of lead ice, J. Geophys. Res.-Oceans, 99, 16341-16350, 1994.

Rabault, J., Sutherland, G., Ward, B., Christensen, K. H., Halsne, T., and Jensen, A.: Measurements of waves in landfast ice using inertial motion units, IEEE T. Geosci. Remote., 54, 6399-6408, 2016.

Rabault, J., Sutherland, G., Jensen, A., Christensen, K. H., and Marchenko, A.: Experiments on wave propagation in grease ice: combined wave gauges and particle image velocimetry measurements, J. Fluid. Mech., 864, 876-898, 2019.

Rabault, J., Sutherland, G., Gundersen, O., Jensen, A., Marchenko, A., and Breivik, $\varnothing .:$ An open source, versatile, affordable waves in ice instrument for scientific measurements in the Polar Regions, Cold Reg. Sci. Technol., 170, 102955, https://doi.org/10.1016/j.coldregions.2019.102955, 2020.

Raghukumar, K., Chang, G., Spada, F., Jones, C., Janssen, T., and Gans, A.: Performance characteristics of "Spotter". a newly developed real-time wave measurement buoy, J. Atmos. Ocean. Tech., 36, 1127-1141, 2019.

Spreen, G., Kaleschke, L., and Heygster, G.: Sea ice remote sensing using AMSR-E 89-GHz channels, J. Geophys. Res.-Oceans, 113, C02S03, https://doi.org/10.1029/2005JC003384, 2008.

Squire, V. A.: Ocean wave interactions with sea ice: a reappraisal, Annu. Rev. Fluid. Mech., 52, 37-60, https://doi.org/10.1146/annurev-fluid-010719-060301, 2020.

Steele, M.: Sea ice melting and floe geometry in a simple ice-ocean model, J. Geophys. Res.-Oceans, 97, 17729-17738, 1992.

Stopa, J. E., Sutherland, P., and Ardhuin, F.: Strong and highly variable push of ocean waves on Southern Ocean sea ice, P. Natl. Acad. Sci. USA, 115, 5861-5865, 2018.

Sutherland, G. and Rabault, J.: Observations of wave dispersion and attenuation in landfast ice, J. Geophys. Res.-Oceans, 121, 19841997, 2016.

Sutherland, G., Rabault, J., Christensen, K. H., and Jensen, A.: A two layer model for wave dissipation in sea ice, Appl. Ocean Res., 88, 111-118, 2019.

The WAVEWATCH III Development Group: User manual and system documentation of WAVEWATCH III version 6.07. Tech. Note 333, Tech. rep., NOAA/NWS/NCEP/MMAB, College Park, MD, USA, 2019.
Thomas, S., Babanin, A. V., Walsh, K. J., Stoney, L., and Heil, P.: Effect of wave-induced mixing on Antarctic sea ice in a highresolution ocean model, Ocean Dyn., 69, 737-746, 2019.

Thomson, J., Ackley, S., Girard-Ardhuin, F., Ardhuin, F., Babanin, A., Boutin, G., Brozena, J., Cheng, S., Collins, C., Doble, M., Fairall C., Guest, P., Gebhardt, C., Gemmrich, J., Graber, H. C., Holt, B., Lehner, S., Lund, B., Meylan, M. H., Maksym, T., Montiel, F., Perrie, W., Persson, O., Rainville, L., Rogers, W. E., Shen, H., Shen, H., Squire, V., Stammerjohn, S., Stopa, J., Smith, M. M., Sutherland, P., and Wadhams, P.: Overview of the arctic sea state and boundary layer physics program, J. Geophys. Res.-Oceans, 123, 8674-8687, https://doi.org/10.1002/2018JC013766, 2018.

Timco, G. and O'Brien, S.: Flexural strength equation for sea ice, Cold Reg. Sci. Technol., 22, 285-298, 1994.

Timco, G. and Weeks, W.: A review of the engineering properties of sea ice, Cold Reg. Sci. Technol., 60, 107-129, 2010.

Vaudrey, K.: Ice Engineering-Study of Related Properties of Floating Sea-Ice Sheets and Summary of Elastic and Viscoelastic Analyses, Tech. rep., Civil Engineering Lab (Navy), Port Hueneme, CA, USA, 1977.

Vaughan, G. and Squire, V.: Scattering of ice coupled waves by a sea-ice sheet with random thickness, Wave. Random Complex, 17, 357-380, 2007.

Voermans, J.: Wave-Ice interactions and ice break-up observations in the Southern Ocean, 2020, Ver. 1, Australian Antarctic Data Centre, https://doi.org/10.4225/15/590173acc61c9, 2020.

Voermans, J., Babanin, A., Thomson, J., Smith, M., and Shen, H.: Wave attenuation by sea ice turbulence, Geophys. Res. Lett., 46, 6796-6803, 2019.

Wang, R. and Shen, H. H.: Gravity waves propagating into an icecovered ocean: A viscoelastic model, J. Geophys. Res.-Oceans, 115, C06024, https://doi.org/10.1029/2009JC005591, 2010.

Williams, T. D., Bennetts, L. G., Squire, V. A., Dumont, D., and Bertino, L.: Wave-ice interactions in the marginal ice zone. Part 1: Theoretical foundations, Ocean Model., 71, 81-91, 2013a.

Williams, T. D., Bennetts, L. G., Squire, V. A., Dumont, D., and Bertino, L.: Wave-ice interactions in the marginal ice zone. Part 2: Numerical implementation and sensitivity studies along 1D transects of the ocean surface, Ocean Model., 71, 92-101, 2013b. 